DOI: 10.20472/IAC.2019.046.009

\author{
NEBOJŠA JANIĆIJEVIĆ \\ University of Belgrade, Faculty of Economics, Serbia
}

\title{
CHALENGING RATIONALISTIC AND OBJECTIVISTIC PERSPECTIVE OF ORGANIZATION
}

\begin{abstract}
:
Institutional theory of organizations, population ecology theory and organizational culture theory are three newer theories that represent alternative and challenge to rationalistic and objectivistic research paradigm in the theory of organization. After a relatively long period in which rationalist and objectivist theories of organizations prevailed, during the second half of the twentieth century three theories emerged that explained the structuring and functioning of organizations from a completely opposite viewpoint. From the 1950s to the 1970s, the dominant theoretical explanation of the structure and processes of all organization types, especially business organizations, was based on the assumption that objective factors and the rationality of decision makers had an impact on organizations. Thus, the contingency theory of organizations explained that the structuring and functioning of organizations resulted from the impact of objective, external factors (contingencies) such as environment, technology, stage of an organization's life cycle and strategies. The process of organizations' structuring and of shaping the processes within them was treated as a rational decision-making process, in which the organization's leader played a key role. The result of such an approach is a configurational perspective of organizations, according to which the organizational structure is actually a configuration of internally consistent components that are congruent to external factors. However, since the 1980s, three very interesting theories have emerged, representing an antipode to the prevailing rationalist and objectivist theories: institutional theory of organizations, population ecology theory and organizational culture theory. All three theories explain the structuring and shaping of processes within organizations in terms of interpretivism and social interactions, and not rational decision making. Unlike the rationalist and objectivist theories of organizations, the organizational culture theory, population ecology theory and institutional theory of organizations, find the ultimate source of organizational structure and functioning in the meaning of the reality that has been socially constructed. The process of organizational structuring is, in all three theories, a subjective process of creating meanings through social interactions. Accordingly, the focus of the institutional, population ecology and cultural theories of organizations is no longer as much on formal organizational structure, as was the case with the contingency theory of organizations, as it is on behavioral patterns, regularities in organizational functioning and the models of interaction within organizations.
\end{abstract}

\section{Keywords:}

Organization

Contingency theory

Institutional theory

Population ecology

Organizational culture

JEL Classification: M10, M14 